\title{
PLANO DE DESENVOLVIMENTO INSTITUCIONAL DE UNIVERSIDADES FEDERAIS BRASILEIRAS
}

\author{
INSTITUTIONAL DEVELOPMENT PLAN FOR \\ BRAZILIAN FEDERAL UNIVERSITIES
}

Recebido em: 09/05/2012 Aprovado em: 28/06/2012 Avaliado pelo sistema double blind review Editora Científica: Manolita Correia Lima

\section{CRISTIAN BAÚ DAL MAGRO crisbau@uceff.edu.br RITA BUZZI RAUSCH UNIVERSIDADE REGIONAL DE BLUMENAU}

\section{RESUMO}

O Plano de Desenvolvimento Institucional - PDI - é um instrumento que fornece informações relevantes sobre as instituições de ensino superior. Essas informações revelam a identidade das universidades e expressam metas e ações visando à qualidade de ensino. Este instrumento serve como apoio ao controle dos recursos financeiros, planejamento de novos investimentos e de novas tecnologias, visando o desenvolvimento. O Ministério da Educação do Brasil - MEC - por meio da lei n ${ }^{\circ}$ I0.86I/04, disponibilizou um modelo base para elaboração do PDI, que serve como pré-requisito para o processo de credenciamento, autorização e reconhecimento de cursos superiores. Diante do contexto, o objetivo da pesquisa foi identificar se os PDI's das Universidades Federais Brasileiras contemplam os requisitos e dimensões estabelecidos pelo MEc. Os procedimentos metodológicos caracterizam o estudo de cunho descritivo, análise documental e quantitativo. Com base na lei e nos requisitos estabelecidos pelo MEc, foi elaborado um check list para facilitar a coleta e análise dos dados. A coleta dos dados foi realizada por meio dos documentos contidos nos sítios eletrônicos das instituições da amostra, constituindose em 24 universidades. Os resultados apontam que nenhuma das universidades pesquisadas evidencia, em seus PDI's, $100 \%$ dos requisitos e dimensões estabelecidos pelo MEc. Verificou-se que apenas cinco universidades estão evidenciando acima de $70 \%$ dos itens, dez universidades evidenciam de $50 \%$ a $70 \%$ dos itens e nove universidades evidenciam menos de $50 \%$ dos itens estabelecidos pelo MEC.Conclui-se que o PDI não é importante para a maioria das Universidades Federais Brasileiras. Os resultados contrariam a importância e relevância dada ao PDI pelo MEC. Palavras-chave: plano de desenvolvimento Institucional; ensino superior; universidades federais brasileiras.

\section{ABSTRACT}

The Institutional Development Plan (PDI) is an instrument that provides relevant information about the Higher Education Institutions in Brazil. Such information reveals the universities' identities and expresses the goals and actions aimed at achieving education quality. The tool can also assist in controlling financial resources and the planning for new investment and technologies, in order to promote development. According to law No. 10.861/04, the Brazilian Ministry of Education $(\mathrm{MEC})$ provided a base model for the PDI to the institutions that serves as a prerequisite to the accreditation, authorization and recognition of higher education courses. Taking this context, the main objective of this research has been to identify whether the PDIS of the Brazilian Federal Universities contemplate the requirements and dimensions that have been set by the MEC. The study is classed as descriptive, quantitative and documentary due to the methodological processes employed. Based on the law and on MEC requirements, a check list was drawn up to facilitate the collection and analysis of data. The collection was accomplished through documents taken from the websites of the sample institutions, which numbered twenty-four. The results indicate that, of the universities surveyed, not one of them has $100 \%$ of the requirements and dimensions set by the MEC in their PDIS. It was found that just five universities contain more than $70 \%$ of the items, ten feature between $50 \%$ and $70 \%$ of the items and nine have less than $50 \%$ of the items. It is concluded that the PDI is not important to most Brazilian Federal Universities. The results contradict the importance and relevance given to the PDI by the MEC.

Keywords: institutional development plan; higher education; brazilian federal universities. 


\section{INTRODUÇÃO}

As transformações que vêm ocorrendo no processo de planejamento das instituições de ensino superior, devido aos avanços tecnológicos, trazem mudanças sociais, econômicas e políticas, e exigem ações para a melhoria na qualidade do ensino.

A qualidade no ensino está diretamente relacionada ao modelo de gestão utilizado pelas universidades. Desta forma, o modelo de gestão burocrático trouxe grandes avanços no passado. No entanto, esse modelo é gerador de extensa burocracia, devido à maior preocupação com aspectos legais e formais dos atos administrativos, deixando em segundo plano a avaliação dos resultados, não atendendo aos desafios de uma sociedade baseada no conhecimento e na informação. Já a gestão focada na avaliação e nos resultados trouxe transformações no planejamento e na gestão das instituições de ensino superior, de forma a atender as demandas por novas tecnologias, geração de conhecimento, eficiência interna e eficácia organizacional.

Nesta perspectiva, se faz necessário observar e elaborar o Plano de Desenvolvimento Institucional (PDI), para reorganizar e planejar a gestão acadêmica e administrativa das universidades federais brasileiras. A construção de uma identidade para as Instituições de Ensino Superior depende de diversos fatores, sendo um deles a implantação de um Plano de Desenvolvimento Institucional que priorize a construção do conhecimento e da cidadania dos acadêmicos.

O PDI é um importante instrumento de auxílio para as Instituições de Ensino Superior. Ele engloba métodos que influenciam na melhoria da qualidade do ensino, uniformidade das tarefas administrativas e gestão financeira eficiente. Com esses pressupostos, ele fornece informações relevantes para as Instituições de Ensino Superior Públicas. Essas informações fazem com que as instituições se mantenham competitivas no mercado e, além disso, controlem eficientemente seus recursos financeiros, viabilizando o investimento em infraestrutura, em profissionais qualificados e em novas tecnologias. 
Para auxiliar as IEs no seu planejamento e gestão, o Ministério da Educação (MEC), criou a Lei n ${ }^{\circ}$ I0.86I, de I4 de abril de 2004, que disponibiliza um modelo para elaboração do PDI, e orienta para que sejam atendidas as dimensões estabelecidas, para a realização dos processos de credenciamento, autorização e reconhecimento de cursos superiores.

No desenvolvimento deste estudo, fica claro que o PDi é um instrumento de apoio ao planejamento e à gestão das instituições de ensino superior. No entanto, o MEC exige que o PDI seja apresentado com várias dimensões. Assim, o presente estudo questiona: Os PDI's das Universidades Federais Brasileiras apresentam os requisitos e dimensões sugeridos pelo MEC?

O presente trabalho tem como objetivo identificar se os PDI's das Universidades Federais brasileiras estão em consonância com os requisitos e as dimensões estabelecidas pelo MEC.

Para atingir o objetivo, este estudo utilizou como amostra as universidades federais brasileiras. Esta escolha justifica-se pela escassez dos recursos financeiros destas instituições e pela alta burocracia administrativa. Com vistas a tais dificuldades, é necessário um Plano de Desenvolvimento Institucional que esteja adequado às dimensões estabelecidas pelo MEC. Este poderia minimizar possíveis perdas por meio de melhores controles dos recursos financeiros, prospecto de visão de longo prazo, planejamento dos investimentos em infraestrutura, novas tecnologias e qualificação profissional.

Diante deste contexto, a pesquisa demonstra sua relevância pela importância do PDI como instrumento de planejamento, gestão e avaliação das IES, visando à melhoria na qualidade do ensino superior brasileiro. 


\section{INSTITUIÇÕES DE ENSINO SUPERIOR}

As instituições de ensino superior são organizações complexas, que se caracterizam pela existência de vários processos produtivos, sendo eles: ensino, pesquisa e extensão. Souza (2005, p. 47) afirma que a "Universidade caracteriza-se por autonomia didática, administrativa e financeira, por desenvolver ensino, extensão e pesquisa, contando com um número expressivo de mestres e doutores.” De acordo com Souza e Silva (1997, p. 74), universidades são instituições pluridisciplinares de formação dos quadros profissionais de nível superior, de pesquisa, de extensão e de domínio e cultivo do saber humano.

As universidades necessitam de recursos para proporcionar especialização profissional e científica. Esses recursos são transformados em serviços e contribuições sociais. Assegurar que as pessoas tenham um alto nível de cultura e qualificação profissional faz parte do objetivo das Instituições de Ensino Superior.

Além das iEs prestarem serviços voltados para o ensino, pesquisa e extensão, também estão inseridas em um mercado competitivo, onde os acadêmicos esperam uma formação de qualidade e excelência. Para que as IES se mantenham no mercado, fica visível a necessidade de implantação de padrões para excelência. ONUSIC (2009) comenta que as IEs buscam satisfazer a formação pedagógica e o ensino aprendizagem dos alunos, exigindo um nível mais avançado de seus dirigentes e do corpo técnico-administrativo.

A transformação do conhecimento com o intuito de modificar a realidade das pessoas é tradicionalmente de responsabilidade das universidades, formando profissionais comprometidos com a sociedade, de forma a conhecer a realidade do seu meio. O ensino superior, para Delors (2000), é o principal instrumento transmissor de conhecimento cultural e científico. Diante da ênfase, as IEs estão mudando seu modo de pensar e agir, buscando atender o objetivo do seu público alvo, por meio de melhoria na formação pedagógica do aluno, no processo de ensino aprendizagem e, também, olhando para aspectos administrativos. 
A qualidade no ensino superior, para Jacob (2003), fica em evidencia nas IES, mas é preciso que todas as partes envolvidas no processo assumam responsabilidade na busca pelo ensino de qualidade. Segundo a autora, esse aspecto fará com que a educação responda a fatores essenciais para sobrevivência, demonstrando, no processo de qualidade, competência, competitividade, produtividade, avaliação, controles, participação, estratégias, foco no discente, nas ações sociais, e na agregação de valor social e econômico. Neste processo, o aluno é papel decisivo. Para Guimarães (2005), se não houver comprometimento, o resultado do serviço ficará afetado, não trazendo a satisfação almejada.

Para uma instituição de ensino superior ter prestígio e ser reconhecida, deve oferecer ensino de qualidade. Guimarães (2005) explica que o ensino de qualidade também está ligado à estrutura disponibilizada pela IEs. Essa estrutura contempla biblioteca com acervo atualizado, fácil acesso à internet, equipamentos e espaço físico adequados para atender às exigências. $\mathrm{Na}$ visão de Masano (2006), a qualidade do ensino não depende apenas da estrutura os departamentos precisam trabalhar em sincronia, contando com horários e locais de atendimento que propiciem maior comodidade aos usuários.

O ensino superior é responsável pela formação de profissionais com habilidades para a tomada de decisões e capazes de enfrentar o ambiente profissional. Santos (1997) comenta que os docentes devem desenvolver atitudes de ação racional e utilizar métodos científicos, com o intuito de preparar o profissional para as decisões que virão a tomar em sua atividade profissional.

Ribeiro (2000) salienta que a avaliação é essencial para a IEs que busca desenvolvimento e qualidade. Assim, o propósito da avaliação institucional é a condução e o aperfeiçoamento constante dos empreendimentos humanos. Balzan e Dias Sobrinho (I995) reafirmam que a avaliação institucional não mede as atividades de forma isolada e não é um mecanismo que expõe as fragilidades ou ineficiências; mas, é promovida como um processo de caráter essencialmente pedagógico. 
O desenvolvimento e a qualidade no ensino também dependem da avaliação constante nos processos de ensino, administrativos e estruturais. O PDI fornece subsídio para que as Ies possam desenvolver um planejamento institucional, que contemple todos os processos, inclusive planejamento de futuras ações. 


\section{PLANO DE DESENVOLVIMENTO INSTITUCIONAL}

O PDI tem suas origens a partir de duas atribuições definidas pela Lei de Diretrizes e Bases da Educação Nacional (LDB), a avaliação institucional e o credenciamento, sendo as mesmas de competência do MEC (BRASIL, I996).

Com a criação do Decreto 3860 de 09 de julho de 200 (BRASIL, 200I), O PDI foi introduzido como um dos elementos do processo de credenciamento de IES. Em dezembro do mesmo ano, o Parecer CNE/CES I366/200I destaca a importância do PDI para determinar a missão de cada instituição bem como suas estratégias para atingir metas e objetivos. Em março de 2002, a Resolução Io/2002 significou uma mudança repentina em relação ao posicionamento do PDI frente ações das instituições de ensino superior.

O decreto $\mathrm{n}^{\circ}$. 3.860, de 9 de julho de $200 \mathrm{I}$ afirma que o Plano de Desenvolvimento Institucional, que se constitui em compromisso da instituição com o MEC, é requisito aos atos de credenciamento e recredenciamento de instituições de ensino superior e poderá ser exigido também no âmbito das ações de supervisão realizadas pelo sESu/MEC.

Em junho de 2002, o MEC, por meio do sistema de Acompanhamento de Processos das Instituições de Ensino Superior (sAPIEns/MEc), publica documento destinado a servir de referencia para a construção do PDI, respondendo duvidas e questionamentos das IEs.

O Ministério da Educação - MEC, com a criação da Lei n ${ }^{\circ}$ Io.86I, de I4 de abril de 2004, iniciou um processo de revisão das atribuições e competências da Secretaria de Educação Superior - sesu, da Secretaria de Educação Profissional e Tecnológica - SETEC, do Conselho Nacional de Educação - CNE e do Instituto Nacional de Estudos e Pesquisa Educacionais - INEP, com o objetivo de consolidar e conferir com maior eficiência e eficácia os dispositivos contidos na Lei $\mathrm{n}^{\circ}$ 9.394, de 20 de dezembro de 1996.

Com a revisão da Lei $n^{\circ} 9.394 / 96$, foi constatada a necessidade de implementar no processo de avaliação das Instituições de Ensino Superior o planejamento estratégico, denominando de Plano de Desenvolvimento Institucional - PDI.O PDI deverá ser apresentado na forma de novo processo nos Sistema SAPIEns, no momento do credenciamento ou o recredenciamento 
periódico das IES no MEC por intermédio do Sistema de Acompanhamento de Processos das Instituições de Ensino Superior - sAPIEns.

As dimensões analisadas pela SESu/MEC e SETEC/MEC tem como objetivo apoiar às instituições no desenvolvimento de seu Plano de Desenvolvimento Institucional - PDI.Assim, o MEC (20II) define que o PDI deve atender as seguintes dimensões, quando da sua elaboração:

a) Perfil Institucional: Histórico da IEs, sua inserção Regional, Missão, finalidades, objetivos e metas, área de atuação acadêmica, responsabilidade social, política de ensino e políticas de extensão e pesquisa.

\section{b) Gestão Institucional:}

I) Organização administrativa: trata sobre a estrutura organizacional, órgãos do colegiado, órgãos de apoio às atividades acadêmicas, autonomia da IEs em relação à mantenedora e a relação e parcerias com a comunidade, instituições e empresas.

2) Organização e gestão pessoal: contemplando os aspectos referentes ao corpo docente e ao corpo técnico/administrativo.

3) Políticas de atendimento aos discentes: completa as formas de acesso, programas de apoio pedagógico e financeiro, estímulos à permanência, organização estudantil e acompanhamento dos egressos.

c) Organização Acadêmica:

I) Organização didático-pedagógica: Plano para atendimento às diretrizes pedagógicas, estabelecendo os critérios gerais para definição de perfil do egresso, seleção de conteúdos, princípios metodológicos, processo de avaliação, práticas pedagógicas inovadoras, políticas de estágio, prática profissional e atividades complementares, políticas e práticas de Educação à distância e políticas de educação inclusiva.

2) Oferta de cursos e programas: As instituições ressalvada a modalidade de ensino a distância, deverão apresentar dados relativos ao número de vagas, dimensões das turmas, turno de funcionamento e regime de matrícula de seus cursos. Informas ainda a situação atual dos cursos, incluindo o cronograma de expansão na vigência do PDI.

d) Infraestrutura: Trata sobre a estrutura física, acadêmica, adequação da infra-estrutura para atendimento aos portadores de necessidades especiais, 
estratégias e meios de comunidade interna e externa e cronograma de expansão da infra-estrutura para o período de vigência do PDI.

e) Aspectos financeiros e orçamentários: Demonstração da sustentabilidade financeira, incluindo os programas de expansão previstos no PDI: Estratégia de gestão econômico-financeira; Planos de investimentos; Previsão orçamentária e cronograma de execução (cinco anos).

\section{f) Avaliação e acompanhamento do desenvolvimento institucional:}

Projeto de Avaliação e acompanhamento das atividades acadêmicas de ensino, pesquisa e extensão, planejamento e gestão; formas de participação da comunidade acadêmica, técnica e administrava, incluindo a atuação da Comissão Própria de Avaliação - CPA, em conformidade com o sistema nacional de avaliação da Educação Superior - SINAEs; e formas de utilização dos resultados das avaliações.

g) Anexos: Projeto pedagógico do curso solicitado para primeiro ano de vigência do PDI. Os projetos dos cursos aqui elencados, para os quais estão sendo solicitada autorização de funcionamento, embora integrando o PDI, deverão constituir arquivos específicos anexados em local apropriado, nas pastas eletrônicas da instituição, no sistema SAPIEns/MEC.

O desenvolvimento do PDi é elaborado para um período de cinco anos e identifica a IES no que diz respeito à sua filosofia de trabalho, à missão a que se propõe, às diretrizes pedagógicas que orientam suas ações, à sua estrutura organizacional e às atividades acadêmicas, que desenvolve ou que pretende desenvolver (BRASIL, 2002).

Diante deste contexto, é visível a necessidade de elaboração do PDI por parte das Universidades Federais. Além disso, faz-se necessário que esteja em consonância com as dimensões estabelecidas pelo MEC. 


\section{METODOLOGIA}

A utilização da característica da pesquisa de forma adequada contribui para que o pesquisador possa adotar as melhores técnicas de coleta e análise dos dados, deixando mais clara as propostas do presente estudo.

A pesquisa, quanto aos objetivos classifica-se como descritiva, por apresentar características de PDI's das Universidades Federais Brasileiras, analisando se estão de acordo com as dimensões estabelecidas pelo MEc. Para melhor entendimento da caracterização da pesquisa descritiva Gil (I999 apud RAUPP; BEUREN, 2006, p. 8I) comenta que "tem como principal objetivo descrever características de determinada população ou fenômeno ou o estabelecimento de relações entre as variáveis.”

A pesquisa quanto aos procedimentos é documental, pelo fato de que foram analisados os PDI's das iEs. Para Colauto e Beuren (2004), a análise documental caracteriza os documentos que serão utilizados, e a determinação fiel dos fenômenos sociais, para em seguida analisar o conteúdo. Ainda Martins e Theóphilo (2007) comentam que é a busca por documentos relevantes para a coleta de informações, dados e evidências.

A abordagem do problema é quantitativa, onde Martins e Theóphilo (2007) afirmam que o pesquisador, dependendo da natureza das informações, dos dados e das evidências, poderá empreender uma avaliação quantitativa, por meio da organização e interpretação de dados numéricos. Assim, para atingir o objetivo do estudo, as análises foram realizadas utilizando-se percentuais de informações encontradas nos PDI's.

A população objeto do estudo é composta pelas universidades federais brasileiras. Assim, a população da presente pesquisa ficou definida por meio das 44 universidades federais brasileiras.

Da população de 44 universidades, sete informaram no site da instituição que seus PDI's estava em fase de atualização e I3 não disponibilizaram seus PDI's de forma on-line no site da instituição. Desta forma, a amostra da pesquisa totalizou 24 universidades, as quais continham seus PDI's disponíveis nos sites. 
Para uma melhor apresentação e detalhamento da população e amostra da pesquisa foi desenvolvida a Tabela I, a seguir.

Tabela 1 População e Amostra da Pesquisa

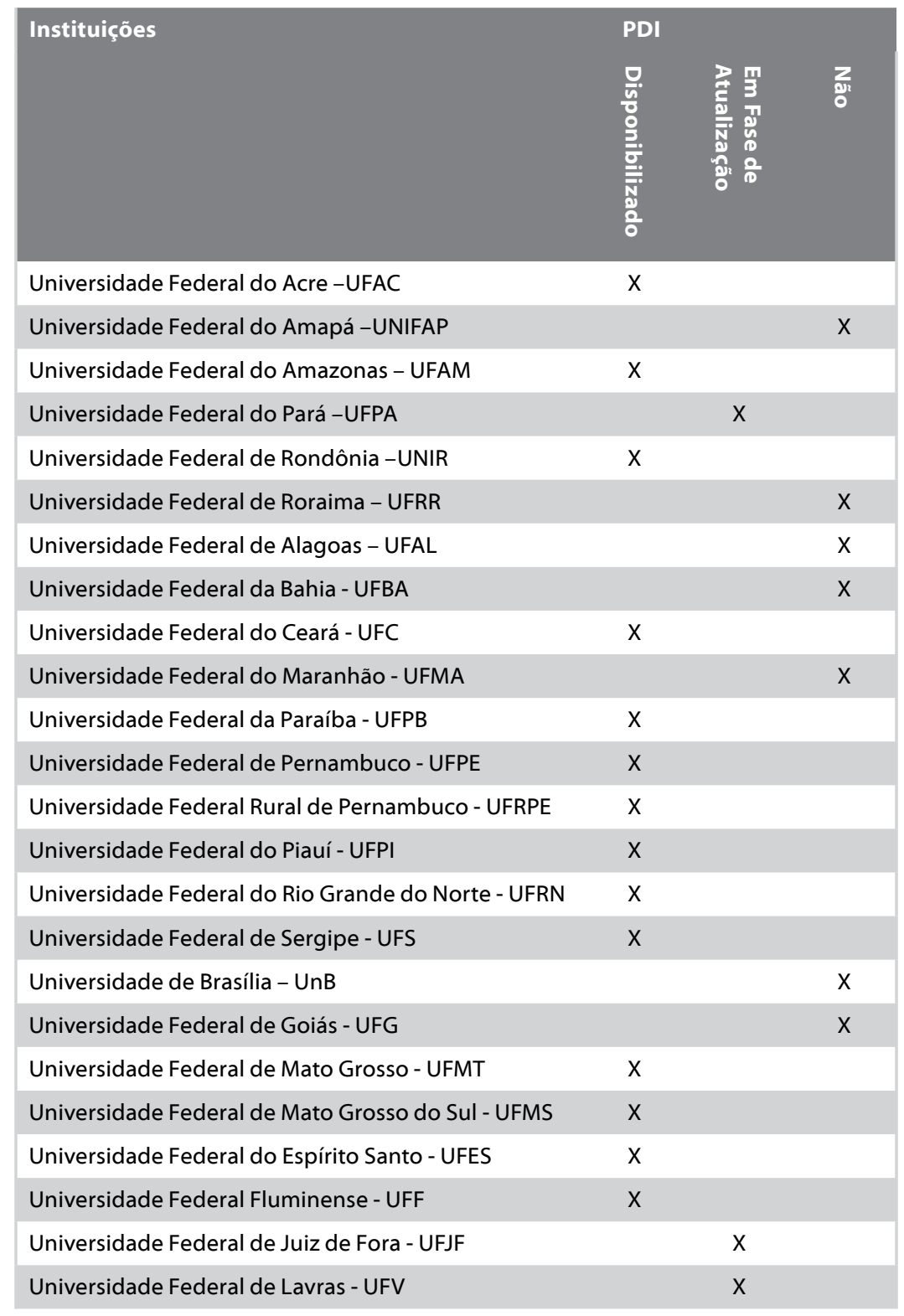




\begin{tabular}{|c|c|c|c|}
\hline \multirow[t]{2}{*}{ Instituiçōes } & \multicolumn{3}{|c|}{ PDI } \\
\hline & 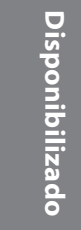 & 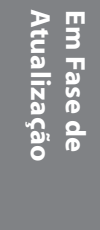 & $\begin{array}{l}z \\
\text { on }^{2}\end{array}$ \\
\hline Universidade Federal de Minas Gerais - UFMG & $\mathrm{X}$ & & \\
\hline Universidade Federal de Ouro Preto - UFOP & & $\mathrm{X}$ & \\
\hline Universidade Federal Rural do Rio de Janeiro - UFRRJ & & & $\mathrm{X}$ \\
\hline Universidade Federal de São Carlos - UFSCAR & $\mathrm{X}$ & & \\
\hline Universidade Federal de São Paulo -UNIFESP & & $\mathrm{X}$ & \\
\hline Universidade Federal de Uberlândia - UFU & & & $\mathrm{X}$ \\
\hline Universidade Federal de Viçosa - UFV & & & $\mathrm{X}$ \\
\hline Universidade Federal do Rio de Janeiro - UFRJ & $\mathrm{X}$ & & \\
\hline Universidade Federal do Rio Grande - FURG & $\mathrm{X}$ & & \\
\hline Universidade Federal do Rio Grande do Sul - UFRGS & $\mathrm{X}$ & & \\
\hline Universidade Federal do Paraná - UFPR & $\mathrm{X}$ & & \\
\hline Universidade Federal de Pelotas - UFPEL & & & $\mathrm{X}$ \\
\hline Universidade Federal de Santa Maria - UFSM & & $\mathrm{x}$ & \\
\hline Universidade Federal de Santa Catarina - UFSC & $\mathrm{X}$ & & \\
\hline Universidade Federal de São João Del Rei - UFSJ & $\mathrm{x}$ & & \\
\hline Universidade do Rio de Janeiro - UNIRIO & $\mathrm{x}$ & & \\
\hline Universidade Federal de Campina Grande - UFCG & $\mathrm{X}$ & & \\
\hline Universidade Federal de Itajubá - UNIFEI & & & $\mathrm{X}$ \\
\hline Universidade Federal de Juiz de Fora -UFJF & & $\mathrm{x}$ & \\
\hline Universidade Federal Rural da Amazônia -UFRAM & & & $\mathrm{x}$ \\
\hline TOTAL & 24 & 07 & 13 \\
\hline
\end{tabular}

Fonte: SESU (2011).

Conforme verificado na Tabela I, a amostra utilizada para a pesquisa ficou delimitada em 24 universidades federais brasileiras, ou seja, $55 \%$ do total da população. É importante destacar que não foram coletados dados das instituições que possuíam seus PDís em fase de atualização, considerando que a análise dos mesmos poderiam ocasionar distorções nos resultados. 
Também houve instituições que não evidenciaram seus PDI's nos sítios eletrônicos, portanto, não fizeram parte da amostra.

A coleta dos dados foi realizada por meio de pesquisa nos sítios eletrônicos das instituições. O objetivo foi reunir o maior número de PDI's divulgados para melhorar a qualidade dos resultados obtidos pela pesquisa.

Como suporte da pesquisa, foi utilizado um check list das dimensões exigidas pelo Ministério da Educação (MEC), quanto à evidenciação do PDI pelas universidades federais brasileiras, conforme apresentado no Quadro I.

Quadro 1 Check List das dimensões do PDI

\begin{tabular}{|c|c|}
\hline \multicolumn{2}{|c|}{ PERFIL INSTITUCIONAL } \\
\hline 1 & Breve Histórico; \\
\hline 2 & Inserção Regional; \\
\hline 3 & Missão; \\
\hline 4 & Finalidades; \\
\hline 5 & Objetivos e Metas; \\
\hline 6 & Área de Atuação Acadêmica; \\
\hline 7 & Responsabilidade Social; \\
\hline 8 & Políticas de ensino; \\
\hline 9 & Políticas de extensão e pesquisa. \\
\hline \multicolumn{2}{|c|}{ GESTÃO INSTITUCIONAL } \\
\hline 10 & Estrutura organizacional, instância de decisão e organograma institucional e acadêmico; \\
\hline 11 & Órgãos colegiados: Atribuições, competências e composição; \\
\hline 12 & Órgãos de apoio às atividades acadêmicas; \\
\hline 13 & Autonomia da IES em relação à mantenedora \\
\hline 14 & Relações e parcerias com a comunidade, instituição e empresas; \\
\hline 15 & $\begin{array}{l}\text { Corpo docente - composição, políticas de qualificação, plano de carreira e regime de } \\
\text { trabalho; }\end{array}$ \\
\hline 16 & $\begin{array}{l}\text { Cronograma e plano de expansão do corpo docente, com titulação e regime de trabalho, } \\
\text { detalhando perfil existente para período de vigência do PDI; }\end{array}$ \\
\hline 17 & $\begin{array}{l}\text { Corpo técnico/administrativo - estruturação, políticas de qualificação, plano de carreira e/ } \\
\text { ou cargos e salários e cronograma de expansão; }\end{array}$ \\
\hline 18 & Formas de acesso, programas de apoio pedagógico financeiro (bolsas); \\
\hline 19 & Estímulos à permanência (programa de nivelamento, atendimento psico-pedagógico); \\
\hline 20 & Organização estudantil (espaço para participação e convivência estudantil); \\
\hline 21 & Acompanhamento dos egressos. \\
\hline
\end{tabular}




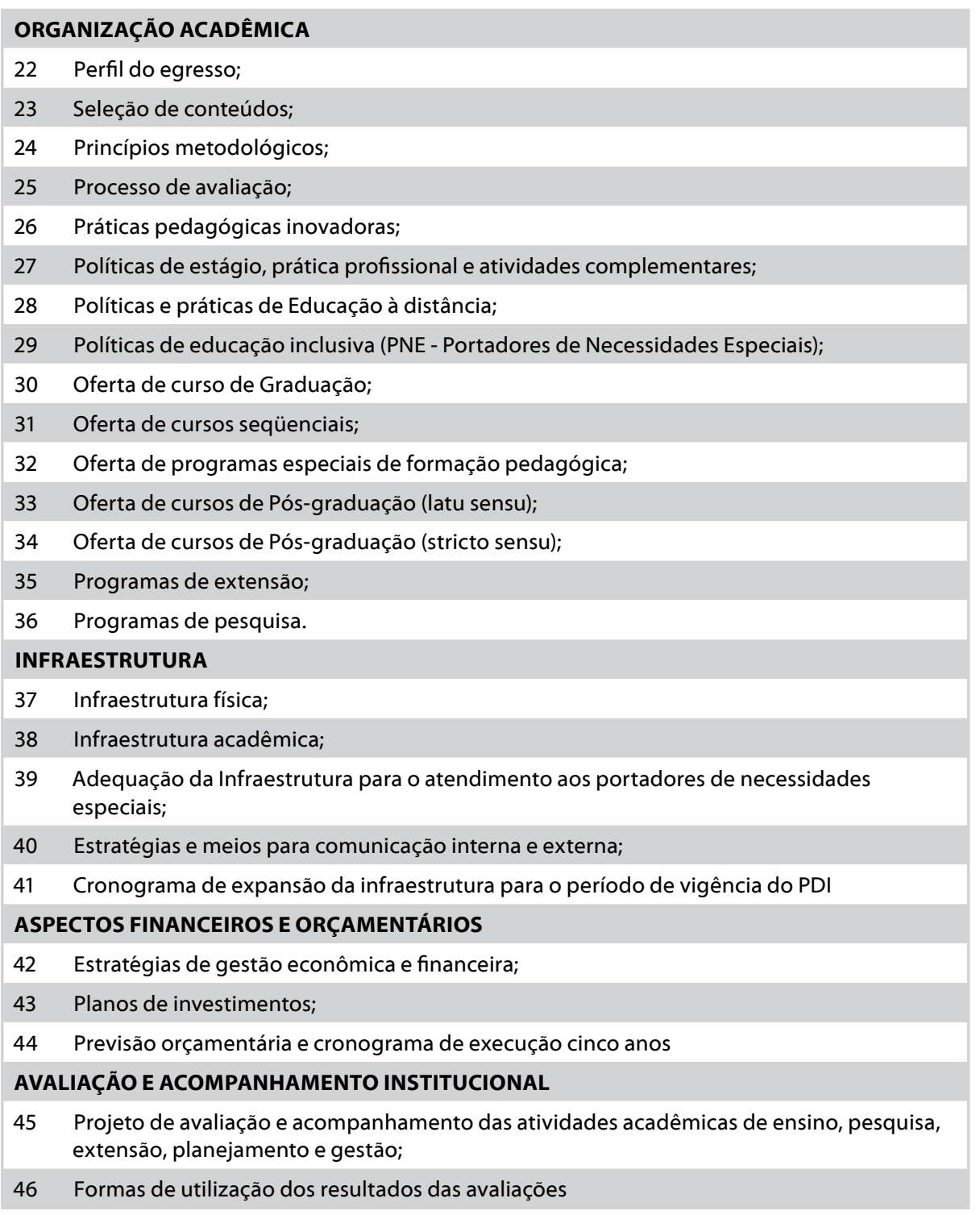

Fonte: Elaborado com base nas Diretrizes do MEC (2011).

Para alcançar os objetivos propostos, foram analisados os PDís das universidades da amostra, averiguando se estavam de acordo as dimensões estabelecidas pelo MEC. Foi utilizado como ferramenta de auxilio o check list exposto no Quadro I. 
Os resultados obtidos por meio da análise dos PDI's, foram transportados para planilhas em excel. Foi utilizado o seguinte procedimento, quando os itens evidenciados pelas universidades correspondem-se as dimensões exigidas pelo MEC, conforme check list, utilizou-se uma variável dicotômica, representada pelo valor I, caso contrário, se a universidade não atendesse tal requisito, o valor caracterizado seria zero.

Desta forma, foi possível verificar uma pontuação de acertos, por meio das evidenciações nos Planos de Desenvolvimento Institucionais das universidades pesquisadas, verificando se estas elaboraram seus PDI's conforme as dimensões exigidas pelo MEC. Foram transformadas as pontuações dos acertos em percentuais, que possibilitaram a construção de tabelas e gráficos para melhor visualização dos resultados. 


\section{RESULTADOS E ANÁLISE DOS DADOS}

O Plano de desenvolvimento institucional é altamente estratégico em virtude do nível de informações divulgadas, motivo pelo qual está sendo constantemente aprimorado e melhorado pelas instituições de ensino superior. Com base nos dados pesquisados e por meio do embasamento teórico, foi verificado se as universidades federais brasileiras estão evidenciando o PDI conforme as dimensões exigidas pelo MEC.

Por meio do check list apresentado nesta pesquisa é possível observar que o PDI é dividido em diversas dimensões que são assim distribuídas: perfil institucional; gestão institucional; organização acadêmica; infraestrutura; aspectos financeiros e orçamentários; e avaliação e desenvolvimento institucional.

A seguir são apresentadas as informações tidas como base para esta pesquisa, além de serem as respostas para alcance do objetivo proposto, conforme apresentado na metodologia pelo check list.

Foi elaborada a Tabela $2 \mathrm{com}$ a finalidade de demonstrar o percentual de evidenciação de cada dimensão do PDI das respectivas universidades constantes na amostra da pesquisa.

Tabela 2 Dimensões do PDI evidenciadas pelas universidades

\begin{tabular}{|c|c|c|c|c|c|c|}
\hline 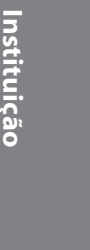 & 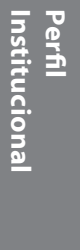 & 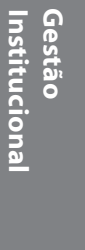 & 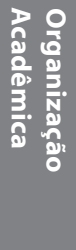 & 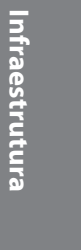 & 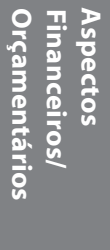 & 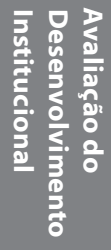 \\
\hline UFC & $78 \%$ & $83 \%$ & $47 \%$ & $80 \%$ & $0 \%$ & $0 \%$ \\
\hline UFPB & $89 \%$ & $83 \%$ & $73 \%$ & $60 \%$ & $67 \%$ & $67 \%$ \\
\hline UFPE & $89 \%$ & $75 \%$ & $67 \%$ & $80 \%$ & $0 \%$ & $100 \%$ \\
\hline UFRPE & $56 \%$ & $33 \%$ & $33 \%$ & $40 \%$ & $33 \%$ & $33 \%$ \\
\hline UFPI & $89 \%$ & $100 \%$ & $73 \%$ & $100 \%$ & $100 \%$ & $100 \%$ \\
\hline UFRN & $67 \%$ & $42 \%$ & $13 \%$ & $0 \%$ & $33 \%$ & $33 \%$ \\
\hline UFS & $67 \%$ & $67 \%$ & $67 \%$ & $80 \%$ & $33 \%$ & $33 \%$ \\
\hline
\end{tabular}




\begin{tabular}{|c|c|c|c|c|c|c|}
\hline 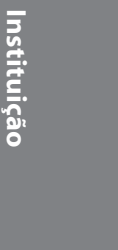 & 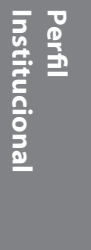 & 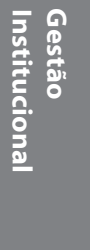 & 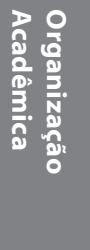 & 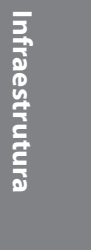 & 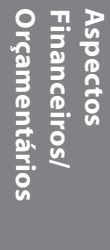 & 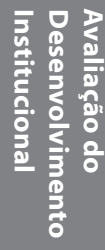 \\
\hline UFMT & $67 \%$ & $75 \%$ & $7 \%$ & $20 \%$ & $0 \%$ & $100 \%$ \\
\hline UFMS & $67 \%$ & $100 \%$ & $73 \%$ & $60 \%$ & $33 \%$ & $100 \%$ \\
\hline UFJS & $33 \%$ & $92 \%$ & $53 \%$ & $100 \%$ & $100 \%$ & $100 \%$ \\
\hline UFAC & $56 \%$ & $67 \%$ & $87 \%$ & $80 \%$ & $33 \%$ & $67 \%$ \\
\hline FUA & $78 \%$ & $42 \%$ & $40 \%$ & $80 \%$ & $100 \%$ & $33 \%$ \\
\hline UNIR & $22 \%$ & $0 \%$ & $7 \%$ & $20 \%$ & $0 \%$ & $0 \%$ \\
\hline UFES & $56 \%$ & $67 \%$ & $73 \%$ & $40 \%$ & $0 \%$ & $100 \%$ \\
\hline UFF & $89 \%$ & $42 \%$ & $40 \%$ & $60 \%$ & $67 \%$ & $33 \%$ \\
\hline UFMG & $100 \%$ & $50 \%$ & $53 \%$ & $80 \%$ & $33 \%$ & $100 \%$ \\
\hline UFSCAR & $33 \%$ & $42 \%$ & $0 \%$ & $20 \%$ & $0 \%$ & $0 \%$ \\
\hline UFRJ & $33 \%$ & $67 \%$ & $0 \%$ & $40 \%$ & $0 \%$ & $0 \%$ \\
\hline UNIRIO & $11 \%$ & $33 \%$ & $33 \%$ & $20 \%$ & $33 \%$ & $100 \%$ \\
\hline UFCG & $22 \%$ & $67 \%$ & $33 \%$ & $0 \%$ & $33 \%$ & $100 \%$ \\
\hline FURG & $56 \%$ & $75 \%$ & $33 \%$ & $80 \%$ & $67 \%$ & $0 \%$ \\
\hline UFRGS & $33 \%$ & $50 \%$ & $53 \%$ & $60 \%$ & $67 \%$ & $0 \%$ \\
\hline UFPR & $100 \%$ & $83 \%$ & $100 \%$ & $100 \%$ & $100 \%$ & $100 \%$ \\
\hline UFSC & $100 \%$ & $83 \%$ & $33 \%$ & $80 \%$ & $100 \%$ & $0 \%$ \\
\hline
\end{tabular}

Verifica-se na Tabela 2 que, na dimensão do perfil institucional listado nos itens I a 9 do check list, três universidades evidenciaram Ioo\% dos itens, sete universidades divulgaram menos de $50 \%$ e I4 divulgaram entre $5 \mathrm{I} \%$ a Io०\% dos itens, ou seja, em um âmbito geral totalizam $7 \mathrm{I} \%$ das instituições pesquisadas.

As universidades que apresentaram menos de $50 \%$ dos itens constantes na dimensão do perfil institucional estão deixando de demonstrar principalmente a áreas de atuação acadêmica, sua inserção regional, as finalidades da instituição, a responsabilidade social, as políticas de ensino e as políticas de pesquisa e extensão.

$\mathrm{Na}$ dimensão da gestão institucional listada nos itens io a 2I do check list, foi verificado que duas universidades divulgaram Ioo\% dos itens, nove 
divulgaram menos de $50 \%$ dos itens. É importante destacar que das nove instituições, que evidenciaram abaixo de $50 \%$, uma não evidenciou nenhum item.

Desta forma, verifica-se que as universidades, que evidenciaram menos de $50 \%$ dos itens da gestão institucional, estão deixando de demonstrar, principalmente, os órgãos de apoio às atividades acadêmicas, autonomia da IES em relação à mantenedora, relações e parcerias com a comunidade, instituição e empresas, estímulos à permanência dos acadêmicos e acompanhamento dos egressos.

$\mathrm{Na}$ organização acadêmica listada nos itens 22 a 36 do check list, apenas uma instituição divulgou 100\% dos itens, por outro lado, duas instituições não divulgaram nenhum item. Destaca-se que, nesta dimensão do total das universidades pesquisadas, II divulgaram menos de $50 \%$ dos itens, ou seja, o inverso das duas dimensões citadas anteriormente.

Em uma análise mais detalhada verifica-se que as universidades que evidenciaram menos de $50 \%$ dos itens da organização acadêmica estão deixando de demonstrar, principalmente, o perfil de seus egressos, a seleção de conteúdos, os princípios metodológicos, o processo de avaliação, as políticas de estágio, a prática profissional e as atividades complementares.

$\mathrm{Na}$ dimensão da infraestrutura listada nos itens 37 a 4I do check list, observa-se que três instituições divulgaram roo\% dos itens, e duas instituições não divulgaram nenhum item. Verifica-se que do total das universidades pesquisadas nove evidenciaram menos de 50\% dos itens.

Detalhando esta análise, observa-se que as universidades que evidenciaram menos de $50 \%$ dos itens da infraestrutura estão deixando de demonstrar fatores de infraestrutura acadêmica, adequações da infraestrutura para $\mathrm{o}$ atendimento aos portadores de necessidades especiais, estratégias e meios para comunicação interna e externa e o cronograma de expansão da infraestrutura para o período da vigência do PDI.

Quanto à dimensão dos aspectos financeiros e orçamentários listado nos itens 42 a 44 do check list, observou-se que quatro universidades divulgaram I0०\% dos itens; por outro lado, sete universidades não divulgaram nenhum dos itens exigidos pelo MEc. Fica destacado que, do total da amostra, apenas 
nove universidades divulgaram mais de 50\% dos itens obrigatórios, ou seja, foi a dimensão onde as instituições evidenciaram os itens em menor proporção.

Observa-se que as universidades que evidenciaram menos de 50\% dos itens referentes aos aspectos financeiros e orçamentários não demonstraram as estratégias de gestão econômico-financeira, os planos para futuros investimentos e a precisão orçamentária e o cronograma de execução para no mínimo cinco anos.

A falta de evidenciação dos aspectos financeiros e orçamentários das universidades federais pode estar ligada à dependência destas instituições por recursos advindos do governo federal.

Por fim, a dimensão da avaliação e o acompanhamento do desenvolvimento institucional, listados nos itens 45 a 46 do check list, foi a que apresentou maior número de instituições, que evidenciaram Ioo\% dos itens exigidos pelo MEC, totalizando dez universidades. No entanto, também foi a dimensão com maior número de instituições que não divulgaram nenhum dos itens exigidos, totalizando sete universidades.

Verifica-se que as universidades que evidenciaram menos de 50\% dos itens referentes à avaliação e ao acompanhamento do desenvolvimento institucional não estão demonstrando seus projetos de avaliação e acompanhamento das atividades acadêmicas de ensino, pesquisa e extensão, planejamento e gestão, as formas de participação da comunidade acadêmica, técnica e administrativa, incluindo a atuação da comissão própria de avaliação e as formas de utilização dos resultados das avaliações.

O Gráfico I apresenta uma média da somatória dos percentuais das dimensões (perfil institucional, gestão institucional, organização acadêmica, infraestrutura, aspectos financeiros e orçamentários, avaliação e acompanhamento institucional) evidenciadas por instituições. 
Gráfico 1 Média da somatória das dimensões por universidade

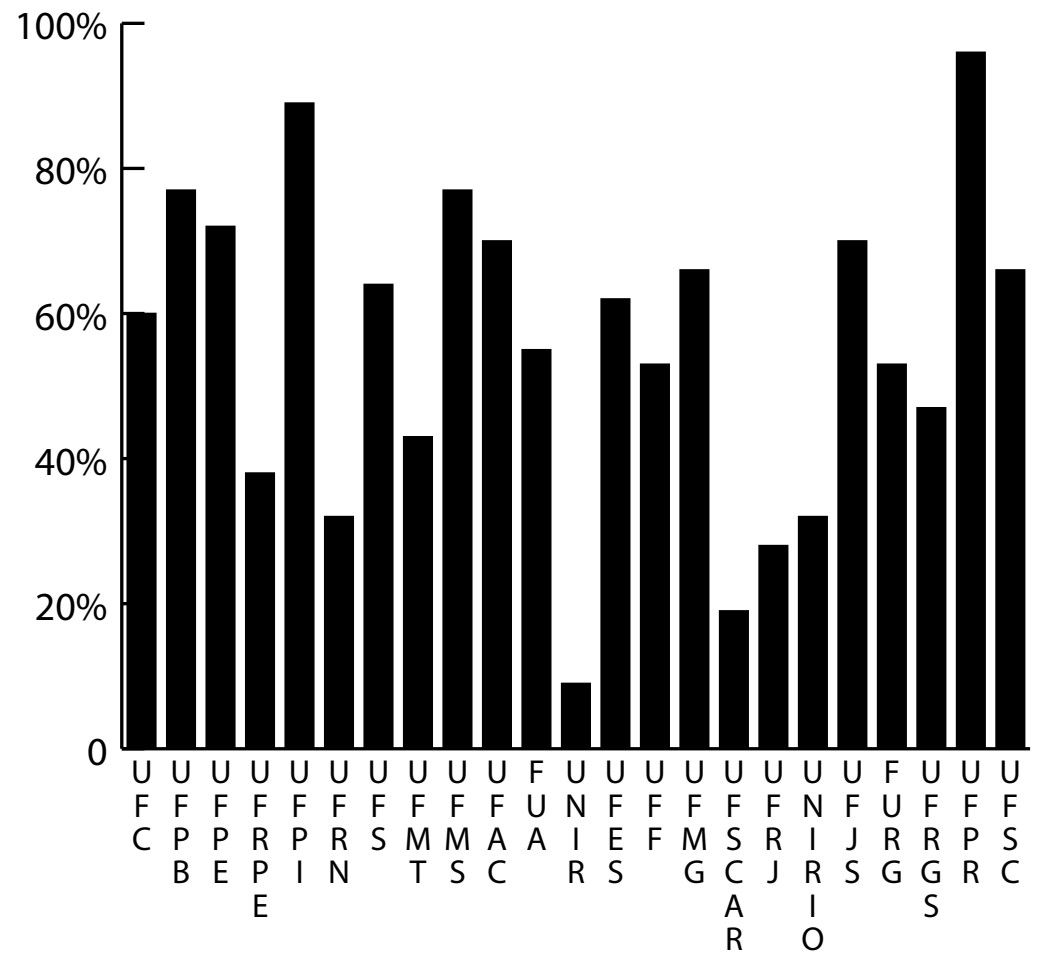

Quanto à somatória total das dimensões divulgadas no PDI das instituições, o Gráfico I demonstra que nenhuma universidade evidenciou 100\% dos itens listados no check list. No entanto, verifica-se que 5 universidades, do total de 24 , divulgaram mais de $50 \%$ dos itens, e apenas nove evidenciaram abaixo de $50 \%$ dos itens.

O Gráfico 2, demonstra a média da somatória dos percentuais das dimensões do PDI por região. 
Gráfico 2 Média da somatória dos percentuais das dimensões do PDI por região

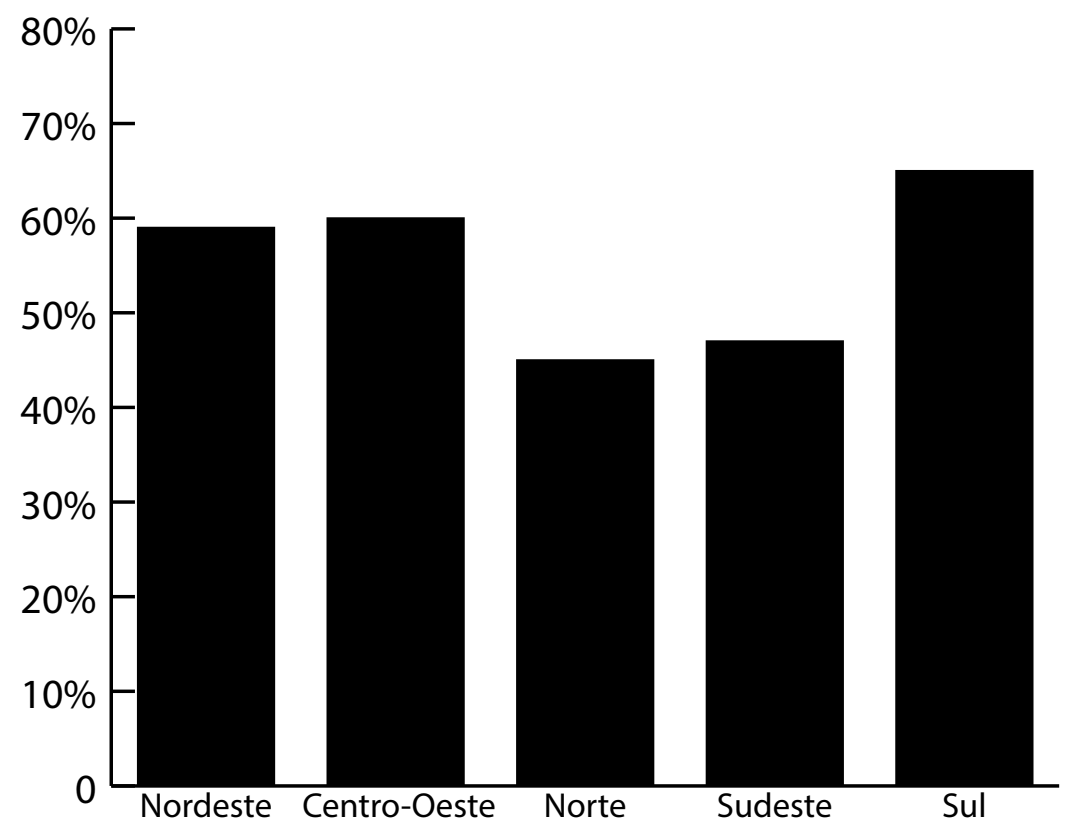

Com base no Gráfico 2, fica claro que as instituições localizadas na região sul do Brasil foram as que mais evidenciaram as dimensões contidas nos itens do check list, totalizando $65 \%$. Já a região norte do Brasil foi a que menos evidenciou as dimensões, totalizando $45 \%$ de evidenciação.

O Ministério da Educação (MEC), estabelece que o PDI deve contemplar um período de cinco anos. Desta forma, o Gráfico 3 demonstra o período de vigência estabelecido nos PDI's das universidades pesquisadas. 
Gráfico 3 Período de vigência do PDI evidenciado em anos

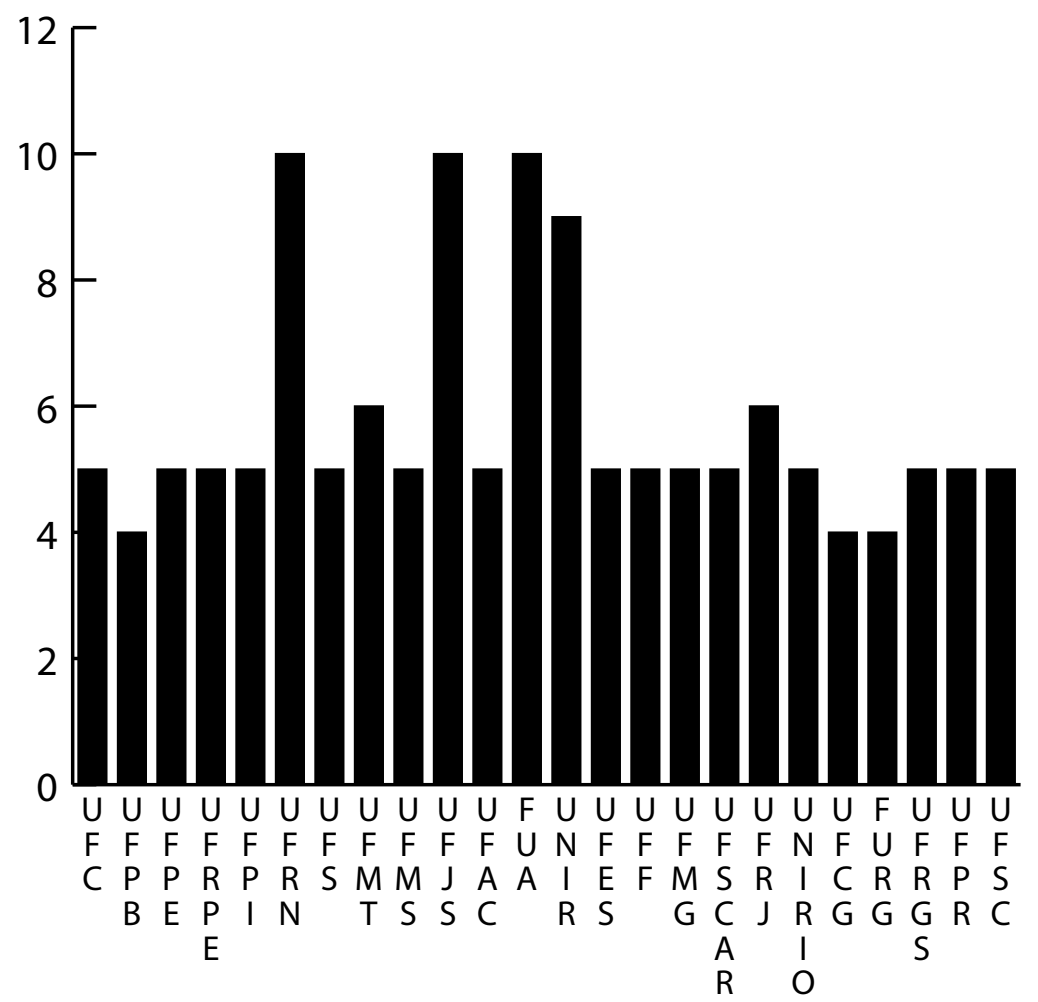

Por meio do Gráfico 3, é possível visualizar que I4 universidades possuem seu PDI com a vigência de cinco anos, totalizando um percentual de $63 \%$ das instituições. E não atenderam à vigência estabelecida seis instituições com um período maior que cinco anos e três com um período menor que cinco anos. 


\section{CONSIDERAÇÕES FINAIS}

Esta pesquisa teve como objetivo identificar se os PDI's das universidades federais brasileiras contemplam as dimensões estabelecidas pelo MEc. Para execução do presente trabalho utilizou-se como base a Lei n ${ }^{\circ}$ Io.86I, de I4 de abril de 2004, que disponibiliza um modelo para elaboração do PDI, servindo como pré requisito para o processo de credenciamento, autorização e reconhecimento de cursos superiores. Assim, por meio da lei n ${ }^{\circ}$ Io.86I, de I4 de abril de 2004 e das dimensões exigidas pelo MEC foi elaborado um check list para facilitar a coleta e análise dos dados.

A análise dos resultados demonstrou que, na dimensão do perfil institucional, I4 universidades divulgaram entre $5 \mathrm{I} \%$ a $100 \%$ dos itens, ou seja, em âmbito geral totalizam $7 \mathrm{I} \%$ das instituições pesquisadas. Considerase que grande parte das instituições demonstra os detalhes do seu perfil institucional pelos resultados apresentados nesta dimensão.

$\mathrm{Na}$ gestão institucional duas universidades divulgaram 100\% dos itens, nove divulgaram menos de $50 \%$ dos itens. É importante destacar que das nove instituições que evidenciaram abaixo de 50\%, uma não evidenciou nenhum item. Assim, observando-se os dados, considera-se que as instituições estão divulgando, parcialmente, os itens referentes ao formato de sua gestão.

Quanto à organização acadêmica apenas uma instituição divulgou 100\% dos itens; já duas instituições não divulgaram nenhum dos itens. Destaca-se que, nesta dimensão, do total das universidades pesquisadas, II divulgaram menos de 50\% dos itens, o inverso das duas dimensões citadas anteriormente.

Observa-se que, na dimensão da infraestrutura, três instituições divulgaram 100\% dos itens; já duas instituições não divulgaram nenhum dos itens e nove evidenciaram menos de 50\% dos itens.

No aspecto financeiro e orçamentário, analisou-se que quatro universidades divulgaram Ioo\% dos itens, por outro lado, sete universidades não divulgaram nenhum item. Fica destacado que, do total da amostra, apenas nove universidades divulgaram mais de 50\% dos itens obrigatórios. 
A avaliação e o acompanhamento do desenvolvimento institucional foi a dimensão com maior número de instituições que divulgou 100\% dos itens, totalizando dez universidades. No entanto, também foi a dimensão com maior número de instituições que não divulgou nenhum item, sete universidades.

Verifica-se que as universidades federais, estão localizadas na região sul do Brasil, são as mais adequadas aos requisitos estabelecidos pelo MEC, quanto ao Plano de Desenvolvimento Institucional. E quanto ao período de vigência, $63 \%$ da amostra total contemplam o PDI para um período de cinco anos.

Conclui-se que as Universidades Federais Brasileiras não elaboram planos, que visam o desenvolvimento institucional. Assim, é exposto que as Universidades Federais Brasileiras possuem pouca preocupação com a reorganização e o planejamento da gestão acadêmica e administrativa. Há pouca ênfase na uniformidade das tarefas e na gestão financeira eficiente. Por fim, não há um planejamento para o controle eficiente dos recursos visando investimentos em infraestrutura, qualificação profissional e inovação tecnológica.

Para pesquisas futuras, recomenda-se comparar os resultados entre IES públicas, privadas e comunitárias. A visão sobre a importância do PDI pode ser diferenciada nas IEs privadas, diante da competitiva exigência na qualidade do ensino superior. Portanto, podem ser obtidos subsídios que argumentem o avanço científico, tecnológico e a melhoria da qualidade no ensino das IEs privadas. 


\section{REFERÊNCIAS}

BALZAN, N. C.; DIAS SOBRINHO, J. (Org.). Avaliação institucional: teorias e experiências. São Paulo: Cortez, 1995.

BRASIL. Lei ñ . 10.861, de 14 de abril de 2004. Institui o Sistema Nacional de Avaliação. Diário Oficial [da] República Federativa do Brasil, Brasília, DF, n. 72, Seção 1, p. 3-4, 15 de abril de 2004.

BRASIL. Lei no. 9.394, de 20 de dezembro de 1996. Estabelece as diretrizes e bases da educação nacional. Diário Oficial [da] República Federativa do Brasil, Brasília, DF, 23 de dezembro de 1996.

BRASIL. Decreto no. 3.860, de 9 de julho de 2001. Dispõe sobre a organização do ensino superior, a avaliação de cursos e instituições, e dá outras providências. Diário Oficial [da] República Federativa do Brasil, Brasília, DF, 10 de julho de 2001.

COLAUTO, R. D.; BEUREN, I. M. Coleta, análise e interpretação dos dados. In: BEUREN, I. M. (Org.). Como elaborar trabalhos monográficos em contabilidade: teoria e prática. São Paulo: Atlas, 2004.

CONSELHO NACIONAL DE EDUCAÇÃO (Brasil). Parecer CNE/CES nº. 1366, de 12 de dezembro de 2001. Dispõe sobre o recredenciamento, transferência de mantença, estatutos e regimentos de instituições de ensino superior, autorização de cursos de graduação, reconhecimento e renovação de reconhecimento de cursos superiores, normas e critérios para supervisão do ensino superior. Diário Oficial [da] República Federativa do Brasil, Brasília, DF, 20 dez. 2001. Seção 1, p. 49.

CONSELHO NACIONAL DE EDUCAÇÃO (Brasil). Resolução nº. 10, de 11 de março de 2002. Dispõe sobre o recredenciamento, transferência de mantença, estatutos e regimentos de instituições de ensino superior, autorização de cursos de graduação, reconhecimento e renovação de reconhecimento de cursos superiores, normas e critérios para supervisão do ensino superior do Sistema Federal de Educação Superior. Diário Oficial [da] República Federativa do Brasil, Brasília, DF, 26 mar. 2002. Seção 1, p. 12.

DELORS, J. Educação: um tesouro a descobrir. 4. ed. São Paulo: Cortez,2000.

GIL, A. C. Métodos e técnicas de pesquisa social. 5. ed. São Paulo: Atlas, 1999.

GUIMARAES, R. T. Avaliação de marca das instituições de ensino superior no segmento de mestrado e doutorado em administração: uma abordagem multivariada. São Paulo, 2005. Tese (Doutorado em Administração) - Faculdade de Economia, Administração e Contabilidade da USP.

INEP - Instituto Nacional de Estudos e Pesquisas Educacionais. Sinopse da educação superior 2009. Disponível em: <http://www.inep.gov.br>. Acesso em: 12/05/2011.

JACOB, R. C. G. Avaliação institucional e indicadores de qualidade nos cursos superiores. Florianópolis, 2003. Dissertação (Mestrado em Engenharia de Produção) - Centro Tecnológico, Universidade Federal de Santa Catarina. 
MASANO, A. C. R. Expectativas e Percepções do Mercado Bancário de Pessoas Físicas de Alta Renda no Município de São Paulo. São Paulo, 2006. Dissertação (Mestrado em Administração) - FEA/Universidade de São Paulo.

MARTINS, G. A.; THEÓFILO, C. R. Metodologia da investigação científica para Ciências Sociais Aplicadas. São Paulo: Atlas, 2007.

ONUSIC, L. M. A qualidade de serviços de ensino superior: o caso de uma instituição de ensino público. São Paulo, 2009. Tese (Doutorado em Administração) - Universidade de São Paulo.

RAUPP, F. M.; BEUREN, I. M. Metodologia da pesquisa aplicável às ciências sociais. In: BEUREN, Ilse Maria. (Org.). Como elaborar trabalhos monográficos em contabilidade: teoria e prática. São Paulo: Atlas, 2004.

RAUPP, F. M.; BEUREN, I. M. Metodologia da pesquisa aplicável às ciências sociais. In: BEUREN, I. M. (Org.). Como elaborar trabalhos monográficos em contabilidade: teoria e prática. 3.ed. São Paulo: Atlas, 2006.

RIBEIRO, C. M. R. Projeto de Avaliação Institucional da Universidade Federal de Goiás. 2000.

SANTOS, S. M. P. dos. O lúdico na Formação do Educador. Vozes: Petrópolis, 1997.

SESU. Disponível em: http://www.mec.gov.br/sesu/ies.shtm. Acesso em: 10/05/2011.

SOUZA, C. C. M. Fatores de qualidade percebidos pelos discentes de cursos de administração de empresas: um estudo sobre as relações da causalidade através da modelagem de equações estruturais. São Paulo, 2005. Dissertação (Mestrado em Administração) Fundação Escola de Comércio Álvares Penteado.

SOUZA, P. N. P.; SILVA, E. B. da. Como Entender e Aplicar a Nova LDB. São Paulo: Pioneira, 1997.

UNESCO. Relatório para a UNESCO da Comissão Internacional sobre Educação para o Século XXI. Tradução de: Learning: the treasure within. 2000. Relatório. 


\section{DADOS DOS AUTORES}

CRISTIAN BAÚ DAL MAGRO^ crisbau@uceff.edu.br Mestrando em Ciências Contábeis pela FURB

Instituição de vinculação: Universidade Regional de Blumenau

Blumenau/SC - Brasil

Áreas de interesse em pesquisa: Orçamento Empresarial, Controladoria e Ensino em Contabilidade.

* Avenida Coronel Ernesto Francisco Bertaso, n 954, Sala 01

Centro Quilombo/SC 89850-000

RITA BUZZI RAUSCH rausch@furb.br

Doutora em Educação pela Unicamp

Instituição de vinculação: Universidade Regional de Blumenau

Blumenau/SC - Brasil

Áreas de interesse em pesquisa: Educação Superior, Planejamento de Ensino e

Docência Universitária. 